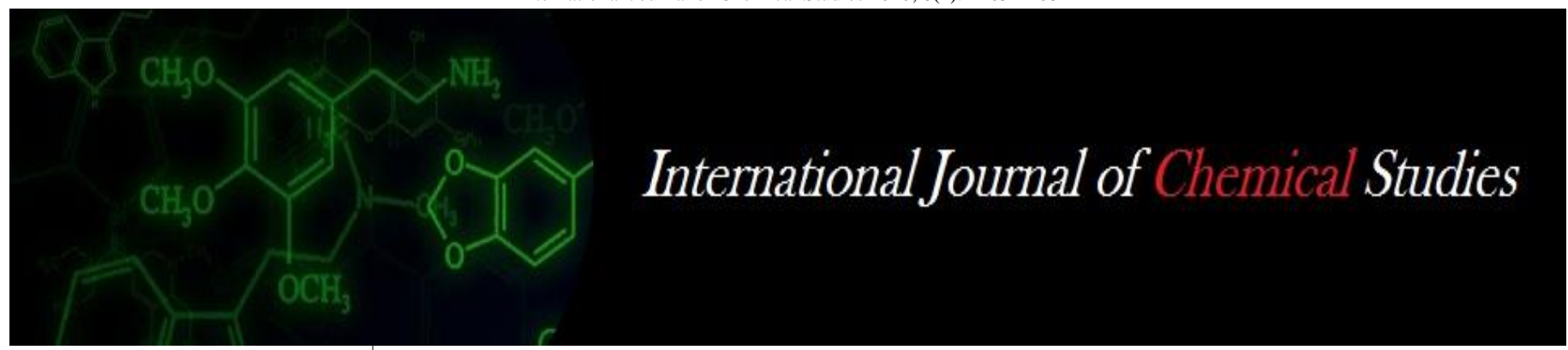

P-ISSN: 2349-8528

E-ISSN: 2321-4902

www.chemijournal.com

IJCS 2020; 8(2): 2265-2268

(C) 2020 IJCS

Received: 15-01-2020

Accepted: 19-02-2020

\section{Shalini Sharma}

Department of Soil Science and

Agricultural Chemistry,

Institute of Agricultural

Sciences, Banaras Hindu

University, Varanasi,

Uttar Pradesh, India

\section{YV Singh}

Department of Soil Science and

Agricultural Chemistry,

Institute of Agricultural

Sciences, Banaras Hindu

University, Varanasi,

Uttar Pradesh, India

Arnab Kundu

Department of Agricultural Chemistry and Soil Science,

Bidhan Chandra Krishi

Viswavidyalaya, Mohanpur,

Nadia, West Bengal, India
Corresponding Author:

YV Singh

Department of Soil Science and

Agricultural Chemistry,

Institute of Agricultural

Sciences, Banaras Hindu

University, Varanasi,

Uttar Pradesh, India

\section{Soil test crop response based gradient experiment of rice (Oryza sativa $L_{\text {.) }}$ ) with NPK fertilizers in alluvial soil of Varanasi}

\author{
Shalini Sharma, YV Singh and Arnab Kundu
}

DOI: https://doi.org/10.22271/chemi.2020.v8.i2ah.9089

\begin{abstract}
Soil Test Crop Response (STCR) studies are very useful for balanced fertilizer recommendation in farmers' field. But before conducing STCR experiment, a gradient experiment is requisite. For that a gradient experiment was conducted in a farmer's field at Varanasi during kharif 2017. The experiment was conducted in three strips (I, II and III) in which three varying doses of NPK fertilizers were applied [low $(0,0,0)$, medium $(120,60,60)$ and high $(240,120,120) \mathrm{kg} \mathrm{ha}^{-1}$ of $\mathrm{N}, \mathrm{P}_{2} \mathrm{O}_{5}$ and $\left.\mathrm{K}_{2} \mathrm{O}\right]$, respectively. Rice (var. HUR105) was grown as exhaust crop. After harvest, grain and straw yields of rice were recorded and plant samples were collected and analyzed for NPK uptake determination. We noticed significant difference on NPK uptake, grain and straw yields, and post-harvest soil test values of rice crop which was the reflection of graded levels of NPK fertilizer application. Fertility gradient was created and the field was ready for further advancement of STCR experiment for fertilizer recommendation.
\end{abstract}

Keywords: Gradient experiment, STCR, Rice, NPK fertilizers and Uptake

\section{Introduction}

Proper soil-fertility management is the prime issue in an endeavor to increase crop productivity. But in the post green revolution era, indiscriminate and blanket application of fertilizers without adequate knowledge leads to exhaustion/inadequacy of nutrients, poor soil fertility status and also hampers crop productivity (Ray et al., 2000) ${ }^{[1]}$. Most importantly, farmers are applying fertilizers without knowing the actual fertility status of his/her field, which is the preliminary hindrance for judicious fertilization in farmers' field. Moreover, declining soil fertility and increasing demand of fertilizers create a crisis, and integrated use organic and inorganic origin plant nutrients is the possible way out from this crisis. Soil Test Crop Response (STCR) based fertilizers recommendation, application of soil test and target yield based fertilizer dose has been recognized as crucial for not only achieving targeted yield of crops but also enhancing the fertility status of the soil. STCR based fertilizer recommendation is valid and apt against the debated approaches namely 'fertilizing the soil' versus 'fertilizing the crop'. Yield targeting based fertilizer recommendation is a unique cultivation package as it not only indicates soil test based fertilizer recommendation but also considers the level of yield that a farmer is expecting/targeting (Velayutham, 1979) ${ }^{[2]}$. The STCR experiments are conducted based on the basic assumption that fertilizer recommendations would depend upon the crop response, in which minimization of spatial variability is performed against every independent variable that can affect crop yield except for the particular nutrient(s) in question. However, many non-fertility variables (like bulk density, soil texture, available water content $e t c$.) and other fertility variables would also significantly influence the crop yield. Ramamoorthy et al. (1967) ${ }^{[3]}$ inaugurated theoretical basis and experimental proof under Indian conditions for the fact that Liebig's law of minimum works equally well for nitrogen, phosphorus and potassium. This principle forms the basis for 'Targeted yield' concept which was developed by Troug (1960) ${ }^{[4]}$. Targeted yield equation is considered as soil-fertilizer based precision farming approach to meet the demand of nutrient for achieving specified yield target (Balasubramanian et al., 1999) ${ }^{[5]}$. Ramamoorthy (1968) ${ }^{[6]}$ developed a quantitative relationship between different measured levels of a single factor (e.g. fertilizer $\mathrm{N}$ ) of crop production with the resultant yield via field experiment. 
In STCR experiment, it is necessary to have wide range of data of control variable (fertilizer) over uncontrolled variable (soil fertility). Since different levels of fertility cannot be possible at the same field, Ramamoorthy and Velayutham (1971 and 1974) ${ }^{[7,8]}$ elaborated Inductive approach and STCR field design in which wide variation is created in the same field and heterogeneity in soil type is reduced.

Before conducing STCR experiment, establishment of a fertility gradient among the experimental field is one of the most important prerequisite for the success of it. In fertility gradient experiment, field is divided into different fertility strips by applying varying doses of fertilizer and exhaust crop was grown for natural transformation of nutrients present in the soil and creation of fertility gradient for test crop experiment. Rice is the most important stable food crop for more than $60 \%$ population of the world. Uttar Pradesh holds $3^{\text {rd }}$ position in respect to production $(13.27 \mathrm{MT})$ in the country
(Economic Survey 2018-19, vol 2). Present experiment was conducted with an objective of successfully developing fertility gradient among the experimental strips for the succeeding test crop of STCR experiment.

\section{Methods and Materials}

The present investigation involved one season of field experiment during kharif 2017 for establishing fertility gradient among the experimental strips and to have significant relationship between soil test values, uptake of NPK and yield of rice. Rice (var. HUR105) was grown as exhaust crop. This fertility gradient experiment was carried out in the farmer's field of Loharpur village of Varanasi. Varanasi is located at $25^{\circ} 18^{\prime} \mathrm{N}, 80^{\circ} 36^{\prime} \mathrm{E}$, and $80.71 \mathrm{~m}$ above mean sea level and comes under subtropical climate with $647.4 \mathrm{~mm}$ rainfall, $30^{\circ} \mathrm{C}$ $\& 18^{\circ} \mathrm{C}$ mean maximum \& minimum temperature during the experiment (Figure 1).

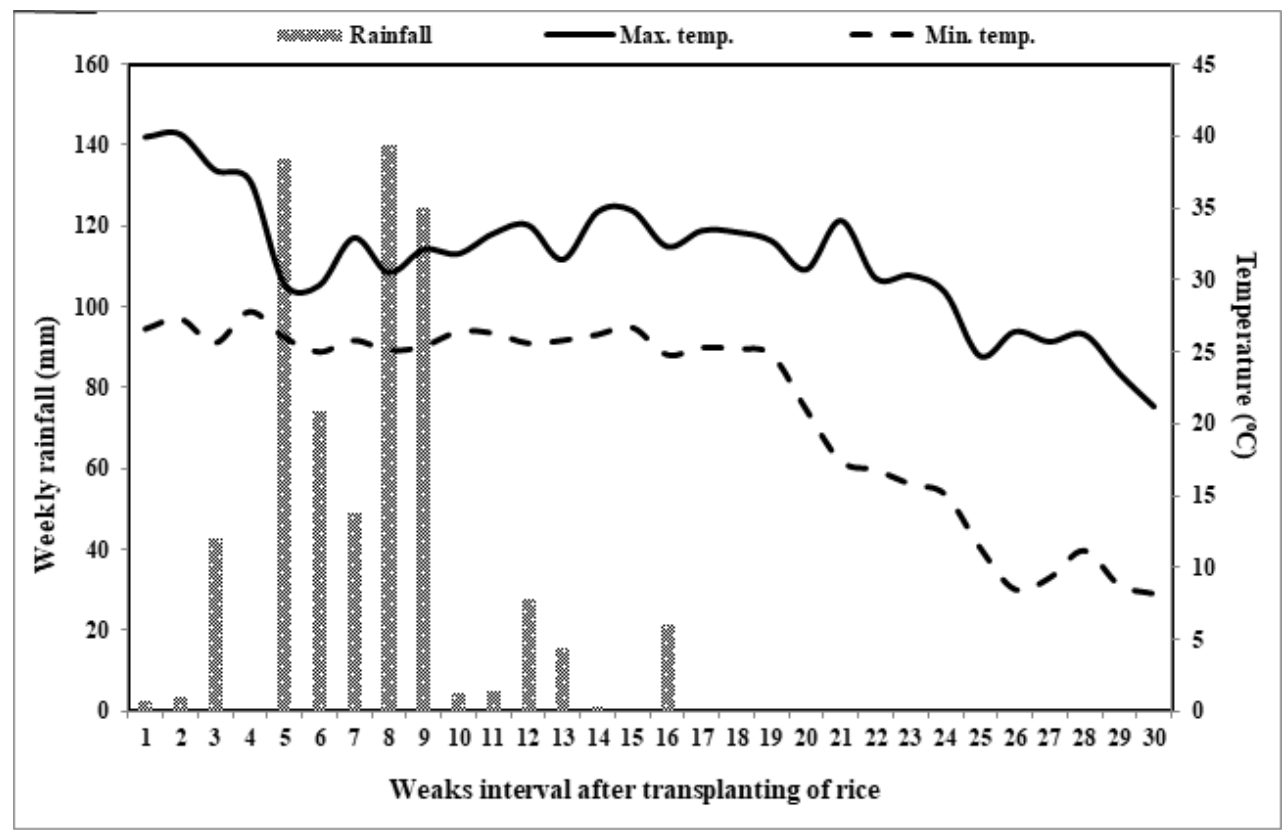

Fig 1: Weather data of experimental site during the experiment

The experimental soil was clay loam texture with slightly alkaline $\mathrm{pH}$ (7.49), $0.243 \mathrm{dSm}^{-1}$ electrical conductivity and medium organic carbon content $(0.57 \%)$. Moreover, the soil was low in available nitrogen (245 $\mathrm{kg} \mathrm{ha}^{-1}$ ), medium in available phosphorus (18.44 $\left.\mathrm{kg} \mathrm{ha}^{-1}\right)$ and medium in available potassium $\left(206 \mathrm{~kg} \mathrm{ha}^{-1}\right)$ status.

Variation in soil fertility was created by adopting the inductive methodology developed by Ramamoorthy, Narasimhan, and Dinesh (1967) ${ }^{[3]}$ and Ramamoorthy and Velayuthum (1971) ${ }^{[7]}$. For this purpose, selected $1269.6 \mathrm{~m}^{2}$ $(52.9 \mathrm{~m} \times 24 \mathrm{~m})$ field was divided into three strips of equal size (strip I, II and III). Healthy 4 weeks old Rice Seedlings were transplanted in the third week i.e. 21st of July in the experimental fields. Different fertilizer doses, low $(0,0,0)$, medium $(120,60,60)$ and high $(240,120,120) \mathrm{kg} \mathrm{ha}^{-1}$ of $\mathrm{N}$, $\mathrm{P}_{2} \mathrm{O}_{5}$ and $\mathrm{K}_{2} \mathrm{O}$, were applied to the $\mathrm{L}_{1}, \mathrm{~L}_{2}$ and $\mathrm{L}_{3}$ strips, respectively. Treatment wise the half of nitrogen and the full dose of phosphorus and potassium were applied as basal. The remaining half dose of nitrogen was top dressed in two equal split doses during tillering stage (28 DAT) and vegetativestage (56 DAT). Zinc sulfate was sprayed twice, one during the tillering stage (33 DAT) and another one during vegetative-stage (25 Days after first application) at the rate of $0.5 \%$ solution. Zinc sulfate $\left(\mathrm{ZnSO}_{4} .7 \mathrm{H}_{2} \mathrm{O}\right)$ solution was prepared by using $2.5 \%$ lime water to neutralize the acidity. The crop was harvested at 120 DAT when foliage started yellowing and grain husk became brownish. Grain and straw yield data were taken and plant samples were collected and analyzed for estimating N, P and K uptake. The samples were oven-dried $\left(65^{\circ} \mathrm{C}\right)$ in a hot air oven. Soil samples $(0-20 \mathrm{~cm}$ in depth) were collected from each experimental strips after harvesting of crop, and collected soils were dried and passed through $2 \mathrm{~mm}$ sieve and analyzed for various soil properties (table 1).

Table 1: Soil parameters and analysis methods

\begin{tabular}{|c|c|}
\hline Soil parameters & Methods followed \\
\hline Organic carbon & Walkley and Black (1965) \\
\hline $\mathrm{pH}$ & Jackson $(1973)^{[10]}$ \\
\hline EC & Jackson $(1973)^{[10\}}$ \\
\hline Available nitrogen & Subbiah and Asija (1956) ${ }^{[11]}$ \\
\hline Available phosphorus & Olsen et al. $(1954)^{[12]}$ \\
\hline Available potassium & Hanway and Heidal (1952) ${ }^{[13]}$ \\
\hline
\end{tabular}

The rice yields, nutrient uptake and soil parameters' data were statistically analyzed by applying one-way design. Duncan's Multiple Range Test (DMRT) was used to compare means through least significant difference (LSD). Statistical analysis 
and interpretation were done by calculating the value of S.Em $( \pm)$ and $C D$ at a $5 \%$ level of significance.

\section{Results and Discussion}

Grain and straw yield: Grain and straw yields of rice were significantly $(\mathrm{p}=0.05)$ differed among different fertility strips as shown in the table 2 . Highest grain yield was obtained from strip III (6.01 $\left.\mathrm{t} \mathrm{ha}^{-1}\right)$ followed by strip II (4.84 $\left.\mathrm{t} \mathrm{ha}^{-1}\right)$ and least from strip I $\left(3.36 \mathrm{t} \mathrm{ha}^{-1}\right)$. Similar trend was found for rice straw yield, as highest straw yield was obtained from strip III (7.83 $\left.\mathrm{t} \mathrm{ha}^{-1}\right)$ followed by strip II $\left(6.23 \mathrm{t} \mathrm{ha}^{-1}\right)$ and least from strip I (4.12 $\left.\mathrm{t} \mathrm{ha}^{-1}\right)$. Highest amount of fertilizers are applied in Strip III which favorably influenced the growth and yield of rice. Obtained higher yield was due to the balanced supply of all important nutrients to the plants. The variations in the yields of rice at different sites in different strips were mainly the consequence of different rates fertilization and associated with soil fertility and the $\mathrm{N}, \mathrm{P}$ and $\mathrm{K}$ uptake ratio by aboveground parts of rice. Plants without fertilizer application exhibited lowest yield due scarcity of available nutrients. These findings were in agreement with findings of other researchers (Pan et al., 1993) ${ }^{[14]}$ (Yousaf et al., 2017) ${ }^{[15] .}$ However, Sridhar and Adeoye (2003) ${ }^{[16]}$ highlighted the ill effects of excessive inorganic fertilizers which may induce nutrient imbalance, soil acidity, and pollution of soil as well as ground water.
Nutrient Uptake: Strip wise nutrient uptake (N, P and K) by the rice was shown in table 2.Mean nitrogen uptake of strip III and II were $70 \%$ and $39.3 \%$ higher than unfertilized strip I, respectively. Mean phosphorus uptake of strip III and II were $59.5 \%$ and $32.1 \%$ higher than unfertilized strip I, respectively. While Mean potassium uptake of strip III and II were 52.2\% and $29.9 \%$ higher than strip I, respectively. A clear cut progressive increment in $\mathrm{N}, \mathrm{P}$ and $\mathrm{K}$ uptake was found from unfertilized strip I to maximum fertilized strip III. This was may be due to the presence of adequate quantity of available nutrients (N, P and $\mathrm{K}$ ) liberated from added fertilizers. Presence of available $\mathrm{N}$ triggered higher amount protein synthesis and vigorous growth, which resulted in higher nutrient uptake (N, P and K). Fertilized plots (strip II and III) had elevated amount of plant available $\mathrm{P}$ which might help in root proliferation, resulting in higher nutrient uptake. Fertilized plots also had elevated amount of potassium in soil which might trigger the plant enzymes and ensuing into greater metabolic activity which contribute to greater nutrient uptake. Mineral $\mathrm{N}$ uptake by rice is associated with biomass production ${ }^{[17]}$. As the production (grain and straw) was higher in fertilized plots, the nutrient uptake was also higher in these plots.

Table 2: Nutrient uptake, grain and straw yield of rice among different fertility strips

\begin{tabular}{|c|c|c|c|c|c|c|c|c|c|}
\hline & & \multicolumn{6}{|c|}{ Fertilizer doses $\left(\mathbf{k g ~ h a}^{-\mathbf{1}}\right)$} & \multicolumn{3}{|c|}{ Rice yield (t ha } \\
\hline
\end{tabular}

Post-harvest soil test values: Highest $\mathrm{pH}, \mathrm{EC}$ and organic carbon were obtained from strip III $\left(7.35,0.294 \mathrm{dSm}^{-1}\right.$ and $0.78 \%$ ) followed by strip II $\left(7.62,0.267 \mathrm{dSm}^{-1}\right.$ and $\left.0.66 \%\right)$ and least from strip I (7.89, $0.236 \mathrm{dSm}^{-1}$ and $\left.0.51 \%\right)$ respectively. Soil $\mathrm{pH}$ had a decreasing trend from highly fertilized strip III to unfertilized strip I. Higher amount of urea application might decrease the soil pH of strip III. Higher root biomass production in fertilized crops might lead to more organic residue addition to the soil, causing higher organic carbon content ${ }^{[18]}$. However, Bejbaruha et al. (2009) [19] found no significant impact of NPK fertilization on soil organic matter or carbon. Higher organic carbon content may positively influence the microbial activity and microbes can liberate higher amount of organic acids which can reduce the soil $\mathrm{pH}$ of strip III. Fertilization can increase the electrical conductivity of soil also.
Similarly, significantly highest available N, P and K contents in soil was obtained from strip III $(255.37,23.36$ and 229.56 $\mathrm{kg} \mathrm{ha}^{-1}$ ) followed by strip II $(245.46,19.42$ and $216.27 \mathrm{~kg}$ $\mathrm{ha}^{-1}$ ) and least from strip I (235.40, 17.35 and $199.81 \mathrm{~kg}$ $\left.\mathrm{ha}^{-1}\right)$.These data reveals that contribution of fertilizer application on soil properties. Strip III had highest fertility status followed by strip II and poor fertility status from strip I as no fertilizer was applied. Significant stock pile of available NPK occurred in strips (II and III) received fertilizer P, compared to strip I in which NPK were never applied. Residual nutrients (NPK) of fertilizers in soil after harvest can significantly contribute to the plant pool during the period of the growth of succeeding crops. Fertilization ensures the constant presence of active microorganisms and regular dynamic of biomass carbon, and these contribute to the maintenance of available nutrient levels in soil ${ }^{[20]}$.

Table 3: Post-harvest soil test values in different fertility gradients after rice harvest

\begin{tabular}{|c|c|c|c|c|c|c|c|}
\hline & & \multicolumn{5}{|c|}{ Post-harvest rice soil test values } \\
\hline Strips & Fertility Gradient & Ph & $\mathbf{E C ~}\left(\mathbf{d S m}^{-\mathbf{1}}\right)$ & $\mathbf{O C}(\mathbf{\%})$ & $\mathbf{A v . ~ N}\left(\mathbf{k g ~ h a}^{\mathbf{- 1}}\right)$ & $\mathbf{A v . ~ P}\left(\mathbf{k g ~ h a}^{\mathbf{- 1}}\right)$ & $\mathbf{A v . ~ K}\left(\mathbf{k g ~ h a}^{\mathbf{- 1}}\right)$ \\
\hline I & L0 & $7.89 \mathrm{a}$ & $0.236 \mathrm{c}$ & $0.51 \mathrm{c}$ & $235.40 \mathrm{c}$ & $17.35 \mathrm{c}$ & $199.83 \mathrm{c}$ \\
\hline II & L1 & $7.62 \mathrm{~b}$ & $0.267 \mathrm{~b}$ & $0.66 \mathrm{~b}$ & $245.46 \mathrm{~b}$ & $19.42 \mathrm{~b}$ & $216.27 \mathrm{~b}$ \\
\hline III & L2 & $7.35 \mathrm{c}$ & $0.294 \mathrm{a}$ & $0.78^{\mathrm{a}}$ & $255.37 \mathrm{a}$ & $23.36 \mathrm{a}$ & $229.56 \mathrm{a}$ \\
\hline SEm $( \pm)$ & & 0.073 & 0.004 & 0.035 & 2.652 & 0.519 & 3.045 \\
\hline CD at 5\% & & 0.253 & 0.015 & 0.119 & 9.17 & 1.795 & 10.53 \\
\hline
\end{tabular}

\section{Conclusion}

From this STCR gradient crop experiment, it can be concluded that graded levels of NPK fertilizer application significantly influenced nutrient uptake, grain and straw yield of exhaust rice crop. As a result post-harvest soil nutrients' status were also affected and fertility gradient was developed 
among the experimental strips. Now the experimental field is ready for further enhancement of that STCR experiment and test crop can be grown for developing fertilizer prescription equations, based on those equations we can recommend fertilizer on target yield basis.

\section{Acknowledgement}

The authors are grateful to Prof. Priyankar Raha, Head of Department of Soil Science Agricultural Chemistry, Banaras Hindu University, for their immense support and encouragement to carry out present research work.

\section{References}

1. Ray PK, Jana AK, Maitra DN, Saha MN, Chaudhury J, Saha $\mathrm{S}$ et al. Fertilizer prescriptions on soil test basis for jute, rice and wheat in Typic Ustochrept. Journal of Indian Society of Soil Science 2000; 48:79-84.

2. Velayutham M. Fertilizer recommendation based on targeted yield concept, problems and prospects, Fertilizer News. 1979; 24(9):12-20.

3. Ramamoorth B, Narasimham RL, Dinesh RS. Fertilizer application for specific yield target of sonara-64 wheat. Indian Farming. 1967; 17:43-45.

4. Troug E. Fifty years of soil testing, Transactions of 7th International Congress of soil Science, Madison Wisconsin, USA, Part III and IV, 1960, 36-45.

5. Balasubramanian V. Farmer adoption of improved nitrogen management technologies in rice farming: technical constraints and opportunities for improvement. Nutrient Cycling in Agro-Ecosystem. 1999; 53:93-101.

6. Ramamoorthy B. Project Coordinator's Report. In First Workshop of the STCR Project, JNKVV, Jabalpur, 1968.

7. Ramamoorthy B, Velayuthum M. Soil-test crop response correlation work in India (World Soil Resources Report No. 41). Rome: Food and Agricultural Organization 1971.

8. Ramamoorthy B, Velayuthan M, Mahajan VK. Recent trends in making fertilizer recommendation based on soil test under fertilizer resource constraints in India. In: Proc. FAI/FAO Natl. Seminar, New Delhi, 1974, 335-346.

9. Walkley A, Black CA. Organic carbon. In Methods of Soil Analysis; Black, C.A. (ed.), Agronomy 9, Part 2 American Society of Agronomy: Madison, Wisc., USA, 1965, 1367-1378.

10. Jackson ML. Soil Chemical Analysis. Prentice Hall of India (Pvt.) Ltd., New Delhi, 1973.

11. Subbiah BV, Asija GL. A rapid procedure for determination of available nitrogen in soils. Current Science. 1956; 25:259-260.

12. Olsen SR, Cole CV, Watanabe FS, Dean LA. Estimation of available phosphorus in soil by extracting with sodium bicarbonate. United State Department of Agriculture Circular, 1954, 989.

13. Hanway JJ, Heidel H. Soil analysis methods asused in Iowa state college soil testing laboratory. Iowa State College of Agriculture Bulletin. 1952; 57:1-31.

14. Pan SG, Huang SQ, Jing Z, Wang JP, Cao CG, Cai ML et al. Effects of $\mathrm{N}$ management on yield and $\mathrm{N}$ uptake of rice in central China. Journal of Integrative Agriculture. 2012; 11(12):1993-2000.

15. Yousaf M, Li J, Lu J, Ren T, Cong R, Fahad S et al. Effects of fertilization on crop production and nutrientsupplying capacity under rice-oilseed rape rotation system. Scientific reports. 2017; 7(1):1-9.
16. Sridhar MKC, Adeoye GO. Organo-mineral fertilizer from urban wastes. The Field. 2003; 68:91-111.

17. Matsushima S. Nitrogen requirements at different stages of growth. In The Minerals Nutrition of the Rice Plant; John Hopkins University Press: Baltimore, MD. 1964, 199-218.

18. Lal S, Mathur BS. Effect of long term application of manure and fertilizer on DTPA-extractable micronutrients in acid soils. Journal of the Indian Society of Soil Science. 1989; 37:588-590.

19. Bejbaruha R, Sharma RC, Banik P. Direct and Residual Effect of Organic and Inorganic Sources of Nutrients on Rice-Based Cropping Systems in the Sub-humid Tropics of India, Journal of Sustainable Agriculture. 2009; 33(6):674-689.

20. Nardi S, Morari F, Berti A, Tosoni M, Giardini L. Soil organic matter properties after 40 years of different use of organic and mineral fertilizers. European Journal of Agronomy. 2004; 21:357-367. 